\title{
Study on Development of Leisure Sports under Modern Society Lintao Ding ${ }^{1, \text { a }}$ \\ ${ }^{1}$ Changzhou University, Jiangsu, Changzhou, 213164 \\ a email
}

\author{
Keywords: Leisure Sports, Modern Society, Development
}

\begin{abstract}
Leisure City, the rise of the city's health is the modern city developed to a certain stage reflects some features, along with the development of urbanization there will be more people living in cities, how healthy development of the city, so the city can become free breathing, feeling happy and joyful life space where local government functions. Leisure Sports is a social, economic and cultural development of the product to a certain extent, as a modern, positive, healthy lifestyle, in line with the needs of modern humanity scientific, civilized and healthy lifestyle. When immersed in a solvent growing leisure sports people's daily lives, has become an important part of daily life, the government assume more responsibility for public services: the distribution of physical infrastructure, provide a variety of leisure and sports activities, and create a good social and leisure atmosphere, providing people with more leisure opportunities.
\end{abstract}

\section{Introduction}

It can be seen from the relevant definition of the concept of leisure sports articles, leisure sports are the main characteristics: freedom and autonomy to participate in the time of disposal, recreational activities and processes based on interest, activities of non-utilitarian mentality and strength the soothing, activity participation and experience physical and psychological effects of one yuan, the diversity of activities and choice of individual, class activities and social significance of the project.

In the study of the value and function of Leisure Sports, Xiao Huanyu in his article from four aspects to explore the value of leisure sports: the value of self-realization, participation in recreational sports can promote physical and mental harmony, improve quality of life; to maintain social stability, improve the social body relationships between, and promote social harmony; good degree of leisure time, spurred a reasonable allocation of leisure time, work and rest, to establish a scientific way of life; leisure sports goods industry, watch leisure sports, leisure and sports tourism and so promote sport for leisure sports industry development, led leisure sports consumption, expanding domestic demand, an increase of more job opportunities. Zhoumei Fang, Cheng et al., From the value of its practice of leisure sports of different ages of view, they think: children participate in recreational sports activities not only improve physical fitness, but also to experience different roles provide more places for them; often teenagers participate in sports and leisure activities to ease learning, work to bring enormous pressure to improve the state of mind in this process of growing youth population can be more aware of their social responsibility; middle-aged groups often participate in sports and leisure activities to maintain and improve the body function, expand interpersonal; and for the older age groups, the greater significance is maintained in contact with the social, health and physical exercise brings enrich their leisure time, improve the quality of life. In the study the interaction between leisure sports and city between Guo Xiu gold by empirical research on Hangzhou, Shanghai and Chengdu three cities found that: the development of leisure sports of city construction has a positive role in promoting: casual sporting events to promote tourism in the city development for the city to create a unique city card; development of leisure sports resources to provide high quality leisure for the city resources to promote the development of urban leisure economy; improving urban lifestyle, leisure sports emphasize the return to nature, the pursuit of the nature of body and mind for the city residents to provide a good, healthy and scientific way of life; and the development of leisure sports can improve urban leisure index, and lay a good foundation for the casual environment of urban construction. 


\section{Historical Change of China Leisure Sports Status and Development}

Emergence of Leisure Sports in the implementation of reform and opening up with the rapid improvement of people's living standards and the new working hours, so that nationals of leisure time ranks among the advanced due. That social transformation in economic change has brought great wealth of material and time, but only material wealth can not be said of leisure sports activities will be able to carry out extensive up. At leisure sports history there is a change in the value of the concept of change and choice, ideas deep change causes a change in human behavior.

Form more diverse, and has a strong stimulating and adventurous social progress makes some traditional items have been better development such as: martial arts, qigong, walking, running, gymnastics and other hand, many scholars from different angles with the scientific means to explore their fitness value; secondly, improvement of living standards, high consumption so that some projects have been developed to become one of the main leisure and entertainment such as: modern tennis, swimming, traveling, home fitness equipment, golf, bowling, racing, motor boats, hang gliding, mountain biking, climbing, cliff climbing, hot air balloon; in this information age of knowledge explosion, and people return to nature trend to adapt, but also towards the mountains recreation sports field development, such as: directional trekking, mountaineering, climbing cliffs, field trips, mountain biking, hiking, adventure, skiing, skating, snowmobiling, beach volleyball; in addition, the spatial development of leisure sports are constantly expanding, and the water from the land towards the direction of high altitude extension such as: canoeing, rowing, windsurfing, jet skiing, diving, surfing, water skiing, fishing, swimming, rafting, hot air ballooning, parachuting.

School sports are closely linked. With the deepening of the reform of school education, school sports have also been positive changes, the school no longer is the cradle of competitive sports, fitness and entertainment but toward the direction of development, the pursuit of health has become the first entertainment sport, fun sport. School sports is not only a major sports and leisure activities, more extensive research is to develop high-quality leisure sports, guiding the main al-Qaida and management of human resources to meet the needs of the community for recreational sports. It has a high purpose of studies sports talent, perspective the value of the existence and development of leisure sport, leisure sport flourished so quickly. In 1983, the famous scholar Mr. Guangyuan proposed to develop school sports play culture, Professor Lu Yuan Town in the 1980s, also pointed out: schools should take on the task of educational pastime.

\section{Situation of Leisure Sports and Problems}

Social Transformation of China's overall operation of society is in a process of transformation. During this period, constantly enrich the material wealth of society, people's income is increasing, decreasing socially necessary labor time and leisure time is increasing. People thought values also change a lot. People yearn for a higher quality of life, which can be more healthy, more happy and enjoy life as important aspect of cultural life) Leisure Sports is continually into people's lives, showing vigor. At present, China Leisure Sports exhibits the following characteristics:

Urban and rural residents leisure fitness programs, generally such as running, badminton, table tennis, swimming, basketball, walking, etc. for the masses loved the project, carried out more widely, East, Central and West are not very different. Some areas of the region with traditional items, such as Yangge, diabolo and other sports as leisure activities, while some emerging such as bowling, golf, aerobics, skating, rock climbing and other new projects as foreign to the popularity, but in China's economy developed regions have undertaken. So there is a big gap between our country and to carry out the Western developed countries, the reason is the difference in economic development between the regions of big result. More importantly, China's social transformation in to a pre-industrial society excessive, according to the standard of Daniel Bell in the coming post-industrial society, a book made, the trend of industrial structure of China's first industry output decreased year by year, the second industry the output value of 5\% of GDP jumped forward, therefore, China generated from post-modernism culture of post-industrial society is still very far away. Western countries and in the form of leisure sports content at the time of rapid development 
of modern culture after production, so the content and form of leisure sports to have a development process With the development of social productivity and development.

Social transformation period, China's sports consumption appears stratification consumption. Currently leisure sports market can be broadly distributed among the consumer sectors summarized as three levels, namely, high-income group, which includes the richest class and the wealthy; the middle class, the so-called well-off class; low-income groups, including the absolute poor, the poor and deprived are ${ }^{1}$. Also known as high-income groups of people get rich first, from the current situation, it is to Liu Yonghao, represented by the large number of private entrepreneurial class. They consume on leisure sports to distinguished type, type of business contacts as the main features of the selected projects are mostly golf, tennis, squash and other luxury items mainly. They can be opened in Sichuan after the board appeared in Beijing two hours a golf course with another president met.

We shall see that in the construction of sports venues and sports capital investment instrument aspect, there is a gap compared to the actual needs from the broad masses of leisure exercise and standards of developed countries. China's sports land area per capita is 1.omZ, and developed more than $2 \mathrm{~m} 2$, the United States reached $14 \mathrm{~m}$, some operators of social charges on 2 entertainment venues fitness is still relatively higher, these factors are not conducive to China Leisure Sports Development. With the social and economic development, relying solely on government investment phenomenon will no longer exist, social, personal and sports lottery set up in the form of donations should increase efforts to gradually form a diversified development and social situation.

\section{Development Strategy of Leisure Sports}

Our overall health and development of sports and leisure are bound to be affected by social processes. Our current society is in the process from a traditional society to a modern social transformation among the great development of mechanization, electrification and the rapid increase in the degree of automation, the popularity of modern means of transport, and information technology, demonstrating a strong productivity, people engaged in various opportunities and productive labor time is greatly reduced; on the other hand, social competition and environmental changes caused by increasing pressure gives the body and mind can fully relax also had urgent needs of the people, and this is today's society to a modern society the Status of transformation. Investigation of leisure sports, it is necessary to grasp the external conditions of life, but also to grasp the needs of leisure sports desire and subjective value choice.

In recent years, the tourism theme of sports tourism in China, set up financing sports and leisure and entertainment as one of the tourism fitness internet. According to statistics, the total number of domestic tourists in 1995 was .639 million passengers, including leisure, entertainment, fitness, rehabilitation for the purpose of accounting for $48.7 \%$ of tourist arrivals. The reasons: First, the public sectors, more and more people have disposable income, become the material basis. Second, the resort is also a sports and leisure resort. Third, the enormous economic benefits of tourism, which is the most important. In 1997, China's tourism earned 1.1 billion, including sports, leisure and entertainment occupy 13. On May 21, according to China Statistical Yearbook 6, 2000, China's tourism revenue reached 451.9 billion yuan, an increase of $12.9 \%$ over 1999 . Where domestic tourism revenue 317.554 billion yuan, an increase of $12.1 \%$ over the previous year, if calculated according to the proportion of 13 sports and entertainment public record, then the record is worth 15.6 billion yuan. In tourism activities, to leisure and fitness for the purpose of sporting activities account for a large proportion. In our country it has been formed sports and tourism combined with each other and promotes each other, common development trend, and this trend will continue to strengthen with the development of the national economy.

Under the planned economy, the national sports goods in terms of variety, quantity, or that from the quality, it is difficult to meet the needs of sports clothing variety, color monotonous, lack of personalized, small sports equipment type, single function, the manufacturing process is also relatively backward. Since the reform and opening up, China's gradual integration into the design of sports to people-centered concept and meet the diverse needs of individual requirements, varieties 
increasingly rich, diverse and functional design has introduced more ergonomic structure of high-tech new products, in order to achieve an effective, safe, comfortable, simple purpose. Especially those with high technological content, entertainment, fitness, testing in one, sophisticated manufacturing technology, multifunctional sports equipment home debut, and began to enter the homes of ordinary people. Such as exercise bikes, miniature treadmill, dancing blankets and so on. Sportswear fashion has become a family, people in the sports apparel putting in pursuit of a personality and brand. Social transformation is resulting in a change in China's sports goods industry, the national sports behavior to modernize a major step forward, truly scientific, systematic, safe, comfortable and effective meaning.

All indications are that production activities and services for the leisure activities carried out is becoming an increasingly important factor in the socio-economic prosperity. Although historically, the city's manufacturing and development is primarily dependent on the prosperity of processing and manufacturing, but now the city has started to change the economic model, increasingly dependent on the prosperity of leisure activities. With the collapse of the city's industrial base and the transfer of the city's economic development will largely depend on a variety of leisure increasingly meet the demand. Sports \& Leisure increasingly high demand for sport and leisure services are also developing well, and in the construction of sports venues and facilities, the design and production of sports equipment, athletic organizations and media, tourism and sports tourism, etc., it can be said involving all sectors. Especially when some foreign new leisure sports activities the introduction of the time, this demand will be rapid development. Develop and thus bring more industry on water sports of skateboarding, sailing, rowing and diving paragliding, air sports, paramotor, hot air ballooning, sports planes, sports. Development of Leisure Sports plays an increasingly important role in economic development.

\section{Conclusion}

Changes in social economic system transition period has brought social and economic development, increasing the supply of social resources, but also for the development of sports and leisure provides the material basis. Transformation of social structure brought to update sports management system, people's ideology but also with social transformation and changed greatly, formed a diversified trend sport values. So we say that social transformation is the historical background of Leisure Sports Development.

\section{References}

[1] Li Qin. Friends of Leisure Sports: Complex harmonious social context of human civilization [J]. Nanjing Institute of Physical Education (Social Science Edition), 2011, 01: 107-109.

[2] Chen Jianguo. the status quo of city leisure sports industry Yuanji Fang Anhui Province, problems and countermeasures [J]. Journal of Chaohu College, 2010,06: 99-102.

[3] Gary Cheek. director of Leisure Constraints two for six cities in China - A ethnographic method [J]. Zhejiang University (Humanities and Social Sciences), Jan. 2009: 31-42.

[4] Li Hongguo restrict plight of Leisure Sports Development of [J]. Wuhan Institute of Physical Education, 2013, 02: 47-51.

[5] Yuan Mingyu. leisure sports stop China's reality Puzzles and Solutions [J]. Physical Education, 2013, 01: 33-37. 